\title{
Evaluation of the paclitaxel-ifosfamide-cisplatin (TIP) combination in relapsed and/or metastatic cervical cancer
}

\author{
C Kosmas ${ }^{*, 1}$, N Mylonakis', G Tsakonas', G Vorgias ${ }^{2}$, N Karvounis', N Tsavaris ${ }^{3}$, T Daladimos', N Kalinoglou², \\ N Malamos ${ }^{4}$, T Akrivos ${ }^{2}$ and A Karabelis' \\ 'Second Division of Medical Oncology, Department of Medicine, 'Metaxa' Cancer Hospital, Pireaus, Greece; 'Department of Gynecology, 'Metaxa' \\ Cancer Hospital, Pireaus, Greece; ${ }^{3}$ Medical Oncology Unit, Department of Pathophysiology-Athens University School of Medicine, Laikon General \\ Hospital, Athens, Greece; ${ }^{4}$ Medical Oncology Unit, Department of Medicine, Helena-Venizelou Hospital, Athens, Greece
}

\begin{abstract}
BACKGROUND: Recurrent or metastatic cervical cancer represents an aggressive malignancy with a high rate of locoregional and distant failure. Therefore, we evaluated the three-drug combination of paclitaxel-ifosfamide-cisplatin (TIP).

METHODS: Systemic chemotherapy-naive patients with advanced metastatic/relapsed cervical cancer and a World Health Organization $(\mathrm{WHO})$ performance status (PS) of 0-2 were eligible. TIP chemotherapy doses were paclitaxel $175 \mathrm{mg} \mathrm{m}^{-2}$ on day I, ifosfamide $2.5 \mathrm{~g} \mathrm{~m}^{-2}$ on days I +2 , and cisplatin $40 \mathrm{mg} \mathrm{m}^{-2}$ on days I +2 , with prophylactic granulocyte-colony stimulating factor.

RESULTS: A total of 42 patients with recurrent/metastatic cervical cancer are evaluable for response and toxicity: median age: 56 (25-74) years; PS: I (0-2); histologies - squamous: 35, adenosquamous: 5, and adenocarcinoma: 2 . Responses were overall response rate (RR): $62 \%$ (95\% confidence interval (Cl): 47.3-76.7\%), with complete response (CR): 26\% (95\% Cl: 12.7-39.3\%), and partial response (PR): 36\% (95\% Cl: 21.5-49.9\%). Responses according to the relapse site were overall RR: 32\% (95\% Cl: 13.7-50.3\%) within previously irradiated pelvis vs 75\% (95\% Cl: 57.7-92.3\%) in extra-pelvic sites. Median time to progression (TTP) was 7 (range, 2-34 +) months and median overall survival (OS) was 16.5 (range, 3-36+) months. Toxicities included grade 3-4 neutropenia: $83 \%$ (21\% febrile neutropenia), grade 3-4 thrombocytopenia: $9 \%$, no grade 3 neuropathy (35\% grade 2), grade 2 asthenia/fatigue 15\%, and no treatment-related deaths.

CONCLUSION: TIP is an active regimen with acceptable toxicity in advanced/relapsed cervical cancer.

British Journal of Cancer (2009) I 0 I, 1059- 1065. doi:I0.1038/sj.bjc.6605305 www.bjcancer.com

Published online 8 September 2009

(C) 2009 Cancer Research UK
\end{abstract}

Keywords: paclitaxel; ifosfamide; cisplatin; chemotherapy; cervical cancer

Paclitaxel represents an established active cytotoxic agent against a wide variety of advanced solid tumours, including gynaecological cancers such as ovarian, uterine, and cervical malignancies. Beyond its early documented activity in relapsed ovarian cancer (Eisenhauer et al, 1994), there are a small number of studies confirming its activity in advanced endometrial carcinoma (Lissoni et al, 1996). Single-agent paclitaxel has shown an initial $17 \%$ activity in advanced cervical cancer at a dose of $170 \mathrm{mg} \mathrm{m}^{-2}$ in 24-h infusion (Thigpen et al, 1995; McGuire et al, 1996), whereas subsequent doses of $250 \mathrm{mg} \mathrm{m}^{-2}$ over $3 \mathrm{~h}$ with granulocyte-colony stimulating factor (G-CSF) support yielded response rates (RRs) of $25 \%$ (Kudelka et al, 1997). Until now, cisplatin has been the most active cytotoxic drug in advanced cervical cancer, and randomised studies applying combinations of first-generation cytotoxic agents with cisplatin had not shown any advantage over single-agent cisplatin. However, a large randomised study conducted by the Gynecologic Oncology Group (GOG) showed that the cisplatinifosfamide combination yielded a $31 \% \mathrm{RR}$, significantly higher

*Correspondence: Dr C Kosmas, 21 Apolloniou Street, Athens GR-163 4I, Greece; E-mail: ckosml@ath.forthnet.gr

Received 3 July 2009; revised II August 2009; accepted I 3 August 2009; published online 8 September 2009 than the cisplatin-mitolactol combination or cisplatin monotherapy, whereas the median time to progression (TTP) was not prolonged significantly: 4.6 vs 3.2 months (Omura et al, 1997). Ifosfamide represents another very active antineoplastic agent in advanced/relapsed cervical cancer (Sutton et al, 1993). The combination of paclitaxel-cisplatin has yielded very encouraging RRs: $50 \%$ in phase II studies (Papadimitriou et al, 1999; Rose et al, 1999). Moreover, the three-drug combination of paclitaxelifosfamide-cisplatin (TIP) has been very active in advanced/ metastatic cervical cancer that has relapsed after surgery \pm radiotherapy (Zanetta et al, 1999), whereas it has shown an $84 \%$ $\mathrm{RR}$ with $16 \%$ pathological CR when applied as neoadjuvant chemotherapy before radical surgery in stages IB2 - IVA (Zanetta et al, 1998).

A phase I study of TIP conducted by our group in various advanced solid tumours has shown the feasibility of administering full doses of each drug with the aid of G-CSF and has established the recommended doses (Kosmas et al, 2000a), and subsequent phase II studies in advanced non-small-cell (Kosmas et al, 2000b) and small-cell lung cancer (Kosmas et al, 2001) have confirmed the feasibility and high anti-tumour activity of the combination.

The aim of this study was to evaluate the feasibility and activity of the TIP regimen in patients with locoregionally relapsed (after radiotherapy \pm surgery) and/or metastatic cervical cancer. 


\section{PATIENTS AND METHODS}

\section{Patient selection}

Consecutive patients with histologically confirmed cervical cancer that had relapsed after previous pelvic radiotherapy \pm surgery or with distant metastases at presentation, which were referred to three collaborating Medical Oncology units, were candidates for treatment with the TIP chemotherapy regimen. Eligibility included the following: (i) patients aged between 18 and 75 years with histologically confirmed cervical cancer not potentially curable by other local measures such as salvage surgery or radiotherapy; (ii) a World Health Organization (WHO) performance status (PS) of $\leqslant 2$; (iii) life expectancy of $\geqslant 3$ months; (iv) adequate haematopoietic (ANC $>1500 \mu \mathrm{l}^{-1}$, PLT $>100000 \mu \mathrm{l}^{-1}$ ), liver (bilirubin $<1.5 \mathrm{mg}$ per $100 \mathrm{ml}$, AST/ALT $<2 \times$ upper normal limit (nl), unless caused by tumour and serum albumin $>3.0 \mathrm{~g}$ per $100 \mathrm{ml}$ ), and renal function (BUN and creatinine $<1.5 \mathrm{nl}$; $\mathrm{nl}=1.5 \mathrm{mg}$ per $100 \mathrm{ml}$ in our laboratory or creatinine clearance $>60 \mathrm{ml} \mathrm{min}^{-1}$ ); (v) no previous systemic chemotherapy (radiosensitising chemotherapy with weekly cisplatin was allowed); (vi) absence of active coronary artery disease (over the last 12 months), unstable diabetes mellitus, or peripheral neuropathy $\geqslant$ grade 2 by the WHO criteria; and (vii) presence of bi-dimensionally measurable disease outside a previously irradiated field, unless there was definite evidence of progression at this site. Patients with isolated progression within the pelvis after radical radiotherapy \pm surgery had to show $a \geqslant 50 \%$ increase in the sum of the products of residual lesions at least 3 months after completion of radiotherapy. Patients with brain metastases were excluded from this study. The study was approved by the Institutional Review Board of the participating institutions, and informed consent was obtained from each patient before study entry according to Institutional policies.

\section{Treatment schedule}

Eligible patients were treated as follows: paclitaxel was administered at $175 \mathrm{mg} \mathrm{m}^{-2}$ over $1-3 \mathrm{~h}$ by intravenous (i.v.) infusion on day 1 , after pre-medication consisting of dexamethasone $20 \mathrm{mg}$, dimethindene maleate (Fenistil) $4 \mathrm{mg}$, and ranitidine $50 \mathrm{mg}$, all administered i.v. $1 \mathrm{~h}$ before paclitaxel administration (Tsavaris et $a l, 1997)$. Ifosfamide was administered at $5.0 \mathrm{~g} \mathrm{~m}^{-2}$ i.v. over $1 \mathrm{~h}$ divided into 2 days (days $1,2: 2.5 \mathrm{~g} \mathrm{~m}^{-2}$ per day; total dose $5.0 \mathrm{~g} \mathrm{~m}^{-2}$ ), together with mesna uroprotection, at $40 \%$ of the ifosfamide dose, given i.v., together with ifosfamide infusion, and at 3 and $6 \mathrm{~h}$ thereafter. Cisplatin was administered at $80 \mathrm{mg} \mathrm{m}^{-2}$ i.v. over $30 \mathrm{~min}$, fractionated for 2 days (days 1, 2: $40 \mathrm{mg} \mathrm{m}^{-2}$ per day; total dose $80 \mathrm{mg} \mathrm{m}^{-2}$ ) with adequate vigorous pre- and posthydration, mannitol and furosemide diuresis, and electrolyte replacement, 20 mequiv. potassium chloride and 8 mequiv. magnesium sulphate per liter of post-hydration solution $(0.9 \%$ normal saline $(\mathrm{N} / \mathrm{S})$ or $1 / 2 \mathrm{~N} / \mathrm{S}+5 \%$ dextrose $(\mathrm{D} 5 / \mathrm{w}))$. The chemotherapy schedule (TIP) was recycled every 21 days.

\section{Supportive care}

Standard anti-emetic medication included ondansetron $24 \mathrm{mg}$ or granisetron $3 \mathrm{mg}$ i.v. $1 \mathrm{~h}$ before chemotherapy at $12 \mathrm{~h}, 8 \mathrm{mg}$ i.v./p.o. or $3 \mathrm{mg}$ i.v./1 mg p.o., respectively, on days 1 and 2 and postchemotherapy ondasetron $8 \mathrm{mg}$ t.i.d./p.o. or granisetron $1 \mathrm{mg}$ p.o. on days 3-5. Dexamethasone $20 \mathrm{mg}$ i.v. was administered $1 \mathrm{~h}$ before chemotherapy (day 1 as paclitaxel pre-medication as well) on days 1 and 2 and post-chemotherapy $4 \mathrm{mg}$ t.i.d. or methylprednisolone $16 \mathrm{mg}$ b.i.d/p.o. on days 3-5 (Kosmas et al, 2000a).

Haematopoietic growth factors included G-CSF $5 \mu \mathrm{g} \mathrm{kg}^{-1}$ s.c. (filgrastim or lenograstim) from day 4 until WBC of $\geqslant 10000 \mu \mathrm{l}^{-1}$ and recombinant human erythropoietin (rh-Epo) of $10000 \mathrm{IU}$ s.c./ t.i.w or $30,000 \mathrm{IU}$ Epoetin-beta or $40000 \mathrm{IU}$ Epoetin-alpha $\times$ $1 /$ week (not on the days of chemotherapy) whenever the haemoglobin $(\mathrm{Hb})$ value dropped $\leqslant 10.5 \mathrm{~g}$ per $100 \mathrm{ml}$ and continued until $\mathrm{Hb} \geqslant 12 \mathrm{~g}$ per $100 \mathrm{ml}$.

\section{Dose modifications for toxicity}

The prerequisites for dose modifications were set as follows: (i) any episode of grade 4 neutropenia of $>7$ days duration, (ii) any episode of febrile $\geqslant$ grade 3 neutropenia, (iii) any episode of grade 4 thrombocytopenia, (iv) any non-haematologic grade 3 or 4 toxicity excluding nausea and vomiting, musculoskeletal and arthritic pain (myalgia/arthralgia syndrome), and alopecia.

The following guidelines were applied with respect to dose reductions for toxicity: (i) For neutropenia, meeting the aforementioned criteria, paclitaxel and ifosfamide doses were reduced by $20 \%$ in subsequent cycles and if toxicity reappeared after a total of $40 \%$ reduction from the starting dose in consecutive cycles, treatment was stopped; however, the patient was evaluable for toxicity and response. (ii) For thrombocytopenia, reduction of cisplatin by $20 \%$ was applied in addition to paclitaxel and ifosfamide dose reductions as specified for neutropenia. (iii) For $\geqslant$ grade 3 mucositis, the doses of paclitaxel and ifosfamide were reduced by $20 \%$ in subsequent cycles. (iv) For neuropathy, $\geqslant$ grade 3 treatment was interrupted. (v) For renal toxicity, $\geqslant 3$ grade toxicity (serum creatinine elevations $>3 \times$ normal) treatment was withheld until recovery (serum creatinine $<1.8 \mathrm{mg}$ per $100 \mathrm{ml}$ ) with cisplatin and ifosfamide administered with further hydration, mannitol diuresis, and hospitalisation in subsequent cycles. (vi) For $\geqslant$ grade 3 CNS toxicity (ifosfamide encephalopathy), the dose of ifosfamide was reduced by $20 \%$ and more hydration with bicarbonates was anticipated in subsequent cycles. In the case that encephalopathy reappeared, ifosfamide was omitted from subsequent cycles.

In the case in which blood counts had not recovered to ANC $\geqslant 1.500 \mu \mathrm{l}^{-1}$ and PLT $\geqslant 100.000 \mu \mathrm{l}^{-1}$ on the day of therapy, treatment was withheld until recovery, and after a maximum delay of 2 weeks, no further therapy was administered.

\section{Pretreatment, follow-up studies, and response evaluation}

Tumour measurements were determined by physical examination and by the specific radiological test that documented measurable disease before treatment. Before the first chemotherapy cycle, a detailed clinical and gynaecological (pelvic) examination, followed by CT scans of the chest/abdomen/pelvis and radionuclide bone scintigraphy, was carried out in all patients. Computed tomography scans of the brain were carried out in the case of suspected brain metastases. Blood counts were checked weekly after each cycle (days 8 and 15) or more frequently in the case of grade 3-4 haematologic toxicity. Evaluation of response was carried out every three cycles of therapy. Patients experiencing toxic death despite objective responses at measurable sites would be categorised as treatment failures. Complete response (CR) is defined as the disappearance of all signs and symptoms of disease for at least 1 month, with the documented disappearance of all known lesions by physical examination, X-rays, CT scans, bone scans, and the development of no new lesions. Partial response $(P R)$ indicates a decrease of $\geqslant 50 \%$ (compared with pretreatment measurements) in the sum of the products of the two largest perpendicular diameters of all measurable lesions and no concomitant growth of new lesions for at least 1 month. There could be no deterioration of symptoms or PS unless secondary to drug toxicity. Stable disease indicates a decrease of $<50 \%$ or an increase in tumour size $<25 \%$ over the original measurements. There could be no deterioration of symptoms or PS unless secondary to drug toxicity. Progressive disease (PD) was defined as an increase of $\geqslant 25 \%$ over the original measurements. 
Full staging evaluation had to be carried out, as reported above, before treatment initiation. Follow-up disease evaluation was carried out at approximately 3-month intervals after the end of treatment.

\section{Statistical methods}

Patients who received at least two cycles of treatment were evaluable for response, unless there was definite evidence of progression after the first cycle for them to be categorised as having PD, and patients who received at least one cycle of treatment were evaluable for toxicity. Response duration was measured from the day of its initial documentation until PD; TTP was calculated from study entry until evidence of PD; OS was measured from the day of entry until last follow-up or death. The 95\% confidence intervals (CIs) for RRs were calculated from the binomial distribution (Cox, 1970). Survival was estimated by the product-limit method of Kaplan-Meier (Kaplan and Meier, 1958). The trial was designed as a phase II study, with RR as the main end point. According to Simon's (1989) two-stage design (Simon, 1989), with a sample size of $n=40$, the study has an $80 \%$ power to accept the hypothesis that true $\mathrm{RR}$ is $>50 \%$, and a $P$ value $<0.05$ to reject the hypothesis that the true RR is $<30 \%$, if $<19$ responses occur. At the first stage, if $<5$ responses occurred out of the initial 16 patients, the study would conclude that the anticipated RR was $<30 \%$ and terminate, with a power $>90 \%$. The study was supervised by the Data Safety Monitoring Board (DSMB) for severe and unacceptable toxicities, and no concern was raised by the investigators and the DSMB regarding safety and efficacy, particularly during the first stage.

\section{RESULTS}

\section{Patients' characteristics}

Between June 2003 and August 2008, 42 patients with relapsed/ metastatic cervical cancer were treated with the TIP chemotherapy regimen. Final data analysis was carried out in March 2009 after all patients entered had completed the planned six cycles of chemotherapy or had interrupted treatment as a result of disease progression or unacceptable toxicity. Patient characteristics and demographics are provided in Table 1 . Median age was 56 years (range, 25-74), and $93 \%$ had a WHO-PS of 0 or 1 , with $7 \%$ of patients having a WHO-PS of 2. Overall, $59.5 \%$ of patients presented with an advanced FIGO stage III or IV (16.7\% with metastatic stage IVB disease). A total of $40.5 \%$ of patients had undergone radical hysterectomy and pelvic lymphadenectomy earlier, and $79 \%$ had undergone an earlier radical radiotherapy in the pelvis. Overall, $17 \%$ of patients had histologies other than squamous carcinoma ( $12 \%$ adenosquamous carcinoma and $5 \%$ adenocarcinoma).

\section{Response to treatment and survival}

Response to TIP chemotherapy was as follows: overall RR: 26 out of 42 (62\%, 95\% CI: $47.3-76.7 \%)$, with CR: 11 out of $42(26 \%, 95 \%$ CI: $12.7-39.3 \%)$ and PR: 15 out of 42 (36\%, 95\% CI: $21.5-49.9 \%)$. Stable disease was observed in 11 out of 42 patients $(26 \%, 95 \%$ CI: $12.7-39.3 \%)$ and PD in 5 out of 42 patients (12\%, 95\% CI: $2.2-21.8 \%)$. Responses were further subdivided according to disease site, that is, within previously irradiated pelvis $v s$ outside pelvis and/or distant sites, and were as follows: overall RR: 8 out of 25 (32\%, 95\% CI: $13.7-50.3 \%)$ in pelvic sites $v s 18$ out of $24(75 \%$, 95\% CI: $57.7-92.3 \%)(P=0.041)$ in extra-pelvic sites (as seven patients had measurable disease at both irradiated pelvis and extra-pelvic sites) (see also Table 2). Moreover, RR after chemoradiation $v s$ others was 15 out of $28(53.5 \%, 95 \%$ CI: $35-72 \%) v s 11$ out of $14(78.6 \%, 95 \%$ CI: $57.1-100 \%)$, respectively $(P=\mathrm{NS}$
Table I Patient characteristics

\begin{tabular}{|c|c|c|}
\hline Characteristic & No. & $\%$ \\
\hline Number of patients & 42 & 100 \\
\hline \multicolumn{3}{|l|}{ Age (years) } \\
\hline Median (range) & $56(25-74)$ & \\
\hline \multicolumn{3}{|l|}{ Performance status (WHO) } \\
\hline 0 & 23 & 55 \\
\hline I & 16 & 38 \\
\hline 2 & 3 & 7 \\
\hline \multicolumn{3}{|l|}{ Histology } \\
\hline Squamous & 35 & 83 \\
\hline Adenosquamous & 5 & 12 \\
\hline Adenocarcinoma & 2 & 5 \\
\hline \multicolumn{3}{|l|}{ Previous treatment } \\
\hline Surgery alone & 2 & 4 \\
\hline Surgery $\rightarrow$ radiation & 5 & 12 \\
\hline Surgery $\rightarrow$ chemoradiation & 10 & 24 \\
\hline Concurrent chemoradiation & 18 & 43 \\
\hline None & 7 & 17 \\
\hline \multicolumn{3}{|l|}{ Sites of tumour involvement } \\
\hline Within prior radiation field (pelvis) & 18 & 43 \\
\hline Outside prior radiation field & 17 & 40 \\
\hline Both & 7 & 17 \\
\hline \multicolumn{3}{|l|}{ Metastatic sites } \\
\hline Lymph nodes & 36 & 86 \\
\hline Pelvic mass & 26 & 62 \\
\hline Lung & 12 & 29 \\
\hline Liver & 3 & 7 \\
\hline Bone & 2 & 4 \\
\hline \multicolumn{3}{|l|}{ No. of sites with tumour involvement } \\
\hline I & 15 & 36 \\
\hline 2 & 23 & 55 \\
\hline$>3$ & 4 & 9 \\
\hline
\end{tabular}

Abbreviation: $\mathrm{WHO}=$ World Health Organization.

Table 2 Response to TIP regimen by disease site

\begin{tabular}{|c|c|c|c|}
\hline & $\begin{array}{c}\text { All } \\
\text { patients }\end{array}$ & $\begin{array}{l}\text { Within irradiated } \\
\text { pelvis }\end{array}$ & $\begin{array}{l}\text { Outside irradiated } \\
\text { pelvis }\end{array}$ \\
\hline Response & No. (\%) & No. (\%) & No. (\%) \\
\hline$C R$ & $11(26)$ & I (4) & $10(42)$ \\
\hline PR & $15(36)$ & $7(28)$ & $8(33)$ \\
\hline SD & II (26) & $12(48)$ & $6(25)$ \\
\hline PD & $5(12)$ & $5(20)$ & $0(0)$ \\
\hline Total & $42(100)$ & $25(100)$ & $24(100)$ \\
\hline
\end{tabular}

Abbreviations: $C R=$ complete response; $P D=$ progressive disease; $P R=$ partial response; $\mathrm{SD}=$ stable disease; $\mathrm{TIP}=$ paclitaxel - ifosfamide - cisplatin.

(nonsignificant), as a result of small numbers). The median duration of response (for CR + PR patients) was 6.5 months and median TTP was 7 months (range, 2 to $34+$ ), whereas the median OS was 16.5 months (range, 3 to $36+$ ) (Figure 1).

\section{Compliance with treatment}

A total of 224 treatment cycles (median: 6 cycles; range, 2-6, mean: 5.33 cycles) were administered. Six patients did not complete the planned six cycles as a result of PD detected after 


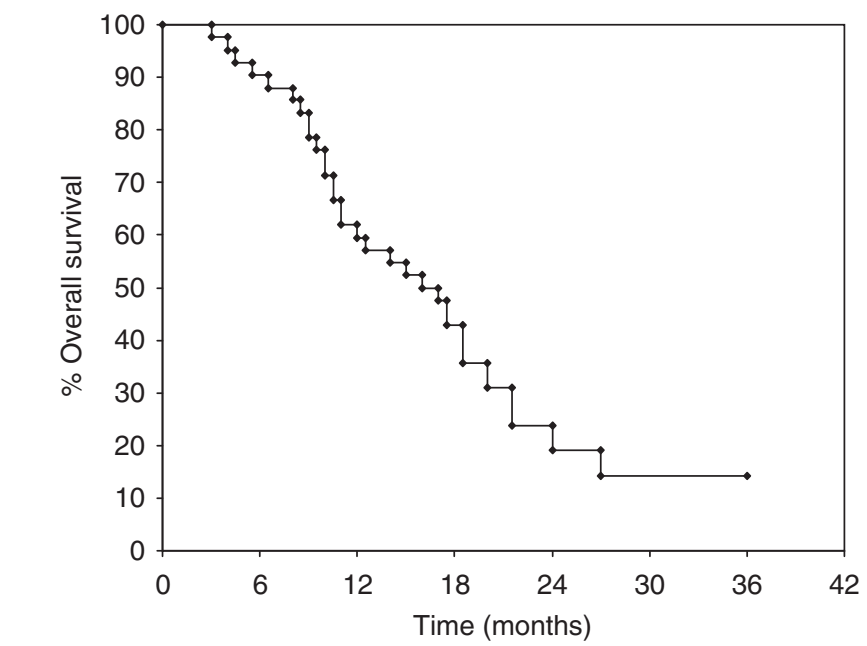

$\begin{array}{llllllll}\text { Patients } & 42 & 38 & 25 & 18 & 8 & 6 & 6\end{array}$

at risk

Figure I Overall survival data of cervical cancer patients treated with TIP.

Table 3 Haematologic toxicities (WHO grade) for TIP

\begin{tabular}{|c|c|c|c|c|c|}
\hline \multirow[b]{2}{*}{ Toxicity } & \multicolumn{5}{|c|}{ WHO grade (\% of patients, all cycles) } \\
\hline & 0 & $\mathbf{I}$ & 2 & 3 & 4 \\
\hline Leukopenia & 0 & 5 & 11 & 30 & 54 \\
\hline Neutropenia & 0 & 4 & 13 & 26 & 57 \\
\hline Thrombocytopenia & 15 & 48 & 28 & 7 & 2 \\
\hline Anaemia & 45 & 24 & 24 & 7 & 0 \\
\hline Febrile Neutropenia & \multicolumn{2}{|c|}{$21 \%$} & & & \\
\hline
\end{tabular}

Abbreviations: TIP = paclitaxel-ifosfamide-cisplatin; $\quad \mathrm{WHO}=$ World $\quad$ Health Organization.

the third cycle in five and after the second cycle in one patient. Four more patients did not complete the planned six cycles as a result of: two dose reductions in successive cycles for haematologic toxicity (as defined above) in two patients after the fourth and fifth cycle, and treatment omission for renal toxicity in two patients (after cycles 2 and 4 ).

\section{Toxicities}

Haematologic and non-haematologic toxicity data for all patients enrolled are summarised in Tables 3 and 4, respectively. Haematologic toxicities (Table 3) consisted primarily of grade 3-4 neutropenia in $83 \%$ ( $57 \%$ grade 4 ) of patients, despite the use of prophylactic G-CSF administration, whereas grade 3-4 thrombocytopenia was encountered in $9 \%$ (2\% grade 4$)$ of patients. Febrile neutropenia was observed in 9 out of $42(21 \%)$ of patients, with 5 of them developing more than one episode. All febrile neutropenic events were managed successfully in the in-patient or outpatient setting by broad-spectrum antibiotics, and there were no treatment-related deaths.

Non-haematologic toxicities (Table 4) consisted primarily of grade $2-3$ nausea and vomiting in 13 out of $22 \%$ patients, grade 1-2 myalgia/arthralgia in 17 out of $33 \%$, and mild grade 1 mucositis in $22 \%$ with no $\geqslant$ grade 2 . Grade 2 peripheral neuropathy was observed in $35 \%$ of patients and usually resolved to $\leqslant$ grade 1 in the majority.
Table 4 Non-haematologic toxicities (WHO grade) for TIP

\begin{tabular}{|c|c|c|c|c|c|}
\hline \multirow[b]{2}{*}{ Toxicity } & \multicolumn{5}{|c|}{ WHO grade (\% of patients, all cycles) } \\
\hline & 0 & I & 2 & 3 & 4 \\
\hline Nausea and vomiting & 24 & 41 & 13 & 22 & 0 \\
\hline Mucositis & 72 & 28 & 0 & 0 & 0 \\
\hline Myalgia/arthralgia & 50 & 17 & 33 & 0 & - \\
\hline Neurologic & & & & & \\
\hline Peripheral & 14 & 51 & 35 & 0 & 0 \\
\hline CNS & 74 & 24 & 2 & 0 & 0 \\
\hline Infection & 93 & 5 & 0 & 2 & 0 \\
\hline Diarrhoea & 51 & 18 & 31 & 0 & - \\
\hline Allergy & 93 & 7 & 0 & 0 & 0 \\
\hline Alopecia & 0 & 0 & 15 & 85 & 0 \\
\hline Asthenia/fatigue & 16 & 38 & 31 & 15 & - \\
\hline Cardiac & 98 & 2 & 0 & 0 & 0 \\
\hline Renal & 96 & 2 & 2 & 0 & 0 \\
\hline Haematuria & 98 & 2 & 0 & 0 & 0 \\
\hline Electrolyte $^{\mathrm{a}}$ & 95 & 5 & 0 & 0 & 0 \\
\hline
\end{tabular}

Abbreviations: CNS = central nervous system; TIP = paclitaxel-ifosfamide -cisplatin; $\mathrm{WHO}=$ World Health Organization. ${ }^{\mathrm{a}}$ Electrolyte toxicity refers to serum potassium $\left(\mathrm{K}^{+}\right)$and magnesium $\left(\mathrm{Mg}^{2+}\right)$ drop.

\section{Dose intensity analysis}

The administered median dose intensities for each drug of the TIP combination were as follows: for paclitaxel $52.0 \mathrm{mg} \mathrm{m}^{-2}$ week $^{-1}$ (range: $48.3-58.3$ ) or $89.2 \%$ (range: $82.2-100 \%$ ) of the planned dose, for ifosfamide $1.5 \mathrm{~g} \mathrm{~m}^{-2}$ week $^{-1}$ (range: $1.2-1.67$ ) or $89.8 \%$ (range: $71.8-100 \%$ ) of the planned dose, and for cisplatin $23.0 \mathrm{mg} \mathrm{m}^{-2}$ week $^{-1}$ (range: $19.6-26.6$ ) or $86.7 \%$ (range: $73.7-$ $100 \%$ ) of the planned dose (Table 5). Therefore, patients received $>85 \%$ of the planned dose intensity for all cytotoxic drugs in the regimen.

\section{DISCUSSION}

Despite significant efforts invested in clinical investigation over the past two decades, the treatment options for patients with locally recurrent/advanced after radiotherapy \pm surgery or de novo metastatic cervical cancer remain limited, and survival for these patients has remained notoriously unchanged and disappointing, with almost no long-term survivors. Cisplatin-based chemotherapeutic regimens in combination with other active drugs have resulted in both higher RRs and prolonged PFS or OS when compared with single-agent cisplatin, as verified in large phase III randomised trials (Omura et al, 1997; Moore et al, 2004; Long et al, 2005). However, the effect of the traditional cisplatin-based combinations in the outcome of recurrent/advanced or metastatic cervical cancer seems to be limited. Therefore, the search for newer two-drug or three-drug cisplatin-based combinations is warranted.

Paclitaxel represents an established active cytotoxic agent against advanced/metastatic cervical cancer at doses between 170 and $250 \mathrm{mg} \mathrm{m}^{-2}$ (McGuire et al, 1996; Kudelka et al, 1997). Ifosfamide represents an oxazaphosphorine alkylating agent that has yielded an 11\% RR in pretreated and a $15.7 \% \mathrm{RR}$ in chemotherapy-naive patients with advanced cervical cancer, whereas at high doses of $3.5 \mathrm{~g} \mathrm{~m}^{-2} \times 5$ days, a $50 \% \mathrm{RR}$ in untreated patients was observed (Cervellino et al, 1990). Moreover, the doublet combinations of ifosfamide + cisplatin and paclitaxel + cisplatin (TP) have shown improved RRs and PFS over singleagent cisplatin in two phase III GOG studies (Omura et al, 1997; Moore et al, 2004).

Preclinical data have shown that paclitaxel intensifies the cellkilling effects of chemically induced DNA damage by alkylating agents and cisplatin, provided that paclitaxel precedes these agents 
Table 5 Dose intensity analysis of TIP in cervical cancer

\begin{tabular}{|c|c|c|c|c|}
\hline Drug & $\begin{array}{l}\text { Planned dose } \\
\text { (every } 3 \text { weeks) }\end{array}$ & $\begin{array}{c}\text { Actual mean DI } \\
\left(\mathrm{mg} \mathrm{m}^{-2} \text { week }^{-1}\right) \text { (range) }\end{array}$ & $\begin{array}{c}\text { Planned DI } \\
\left(\mathrm{mg} \mathrm{m}^{-2} \text { week }^{-1}\right)\end{array}$ & $\begin{array}{c}\% \text { of } \\
\text { planned DI }\end{array}$ \\
\hline $\begin{array}{l}\text { Paclitaxel } \\
\text { Ifosfamide } \\
\text { Cisplatin }\end{array}$ & $\begin{array}{l}175 \mathrm{mg} \mathrm{m}^{-2} \\
5.0 \mathrm{~g} \mathrm{~m}^{-2} \\
80 \mathrm{mg} \mathrm{m}^{-2}\end{array}$ & $\begin{array}{l}52.0(48.3-58.3) \\
1.50(1.2-1.67) \\
23.0(19.6-26.6)\end{array}$ & $\begin{array}{c}58.3 \\
1.67 \\
26.6\end{array}$ & $\begin{array}{l}89.2(82.2-100) \\
89.8(71.8-100) \\
86.7(73.7-100)\end{array}$ \\
\hline
\end{tabular}

Abbreviations: $\mathrm{DI}=$ dose intensity; $\mathrm{TIP}=$ paclitaxel-ifosfamide - cisplatin.

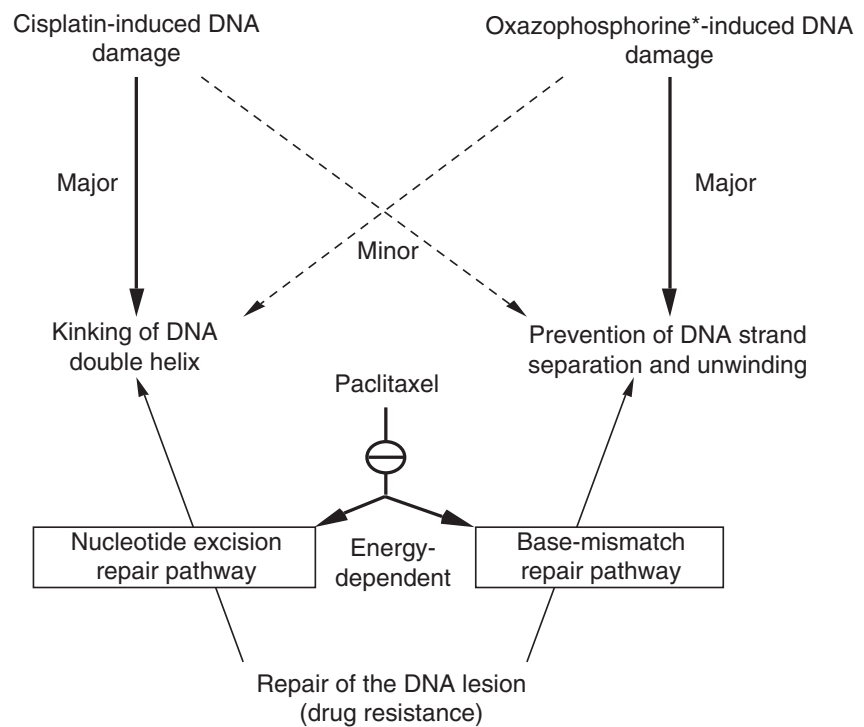

Figure 2 Paclitaxel inhibition of repair of the DNA damage induced by cisplatin and oxazaphosphorine *(cyclophosphamide or ifosfamide) cytostatics (adapted and modified from Reed et al, 1995).

(Parker et al, 1993, Liebmann et al, 1994). In the clinical setting, paclitaxel has shown enhanced activity and possibly synergistic effects when combined with alkylating agents, cyclophosphamide and ifosfamide (Bunnell et al, 1998), or cisplatin (Rowinsky et al, 1993). The proposed mechanisms of in vitro and in vivo synergism are provided in Figure 2 (see also Lind et al, 1989; Reed et al, 1995).

Establishment of the recommended doses of each agent, paclitaxel, ifosfamide, and cisplatin, was based in our previous phase I study of TIP (Kosmas et al, 2000a); however, we elected to reduce the recommended dose of cisplatin from 100 to $80 \mathrm{mg} \mathrm{m}^{-2}$ (divided over 2 days) to compensate for imminent toxicity, particularly in patients exposed to previous pelvic radiotherapy.

The TIP regimen as applied in this study yielded efficacy and survival figures comparable with those obtained in three other published studies (Zanetta et al, 1999; Dimopoulos et al, 2002; Choi et al, 2006). The study by Zanetta et al (1999) evaluated a mixed population of 45 patients with inoperable advanced and/or metastatic cervical carcinoma, with 14 out of 45 patients having never had pelvic irradiation earlier, and 10 patients who underwent locoregional surgery with radical hysterectomy/pelvic \pm paraortic lymphadenectomy after a favourable response to TIP essentially having the role of neoadjuvant/induction chemotherapy. An ORR was seen in $67 \%$ of patients with a $75 \%$ RR in non-irradiated and $52 \% \mathrm{RR}$ in previously irradiated pelvic areas. Overall survival at the time of publication for patients with CR, PR, and non-responders was $13+, 9+$, and 6 months, respectively. Although the authors report a high incidence, that is, $91 \%$, of grade 3-4 myelotoxicity, they do not provide any data on the incidence of febrile neutropenia. Moreover, prophylactic G-CSF was not routinely administered to all patients, but only as secondary prophylaxis after significant myeloid lineage toxicity, and the regimen was modified to a $50-\mathrm{mg} \mathrm{m}^{-2}$ dose of cisplatin in patients who had undergone pelvic radiotherapy earlier $\left(v s 75 \mathrm{mg} \mathrm{m}^{-2}\right.$ for non-irradiated patients) with a 24-h infusion of paclitaxel $175 \mathrm{mg} \mathrm{m}^{-2}$ and ifosfamide $5.0 \mathrm{~g} \mathrm{~m}^{-2}$. In a more recent randomised phase II study of the same group evaluating neoadjuvant TIP $v s \mathrm{TP}$, aiming towards radical surgery in chemotherapy- and radiotherapy-naive patients, the incidence of grade 3-4 neutropenia was $76 \%$ for TIP $v s 26 \%$ for TP without routine prophylactic G-CSF (Lissoni et al, 2009).

In the study by Dimopoulos et al (2002), ORR was $46 \%$ $(\mathrm{CR}=19 \%+\mathrm{PR}=27 \%)$ with an 11.5 -month median response duration, 8.3-month median TTP, and 18.6-month median OS. It should be noted that despite the apparently adequate doses applied (paclitaxel $175 \mathrm{mg} \mathrm{m}^{-2}$, cisplatin $75 \mathrm{mg} \mathrm{m}^{-2}$, and ifosfamide $4.5 \mathrm{~g} \mathrm{~m}^{-2}$, divided over 3 days), the regimen was less intense, as it was administered at an intended 4-week interval, contrary to the usual 3-week interval pertaining to our and the other published studies so far (Zanetta et al, 1999; Choi et al, 2006). Despite routine G-CSF prophylaxis, a $26 \%$ incidence of grade 4 neutropenia was reported.

In the more recently published study by Choi et al (2006), ORR was $46.7 \% \quad(\mathrm{CR}=4.4 \%+\mathrm{PR}=42.2 \%)$ with a median $\mathrm{TTP}$ of 8.0 months and OS of 19 months. However, in this latter study, an appreciable number of patients, 17 out of $45(38 \%)$, received TIP as second-line chemotherapy after failure of first-line cisplatin + 5-FU, and this group fared significantly worse in terms of ORR and survival compared with those who received TIP as first-line chemotherapy (Choi et al, 2006). Drug doses in this study were lower than those in all other published studies, namely paclitaxel $135 \mathrm{mg} \mathrm{m}^{-2}$, cisplatin $50 \mathrm{mg} \mathrm{m}^{-2}$, and ifosfamide $3.0 \mathrm{~g} \mathrm{~m}^{-2}$, divided over 3 days at 3 -week intervals, justified by the authors as a result of previous pelvic irradiation in the majority of patients (96\%). However, only seven episodes of febrile neutropenia were recorded (out of 253 cycles) without routine prophylactic G-CSF, and the incidence of $>$ grade 2 peripheral neuropathy was $21 \%$, the latter rather as a result of previous extensive systemic cisplatin chemotherapy.

Our results, with an ORR of $62 \%(C R=26 \%+P R=36 \%)$, a median TTP of 7 months, and a median OS of 16.5 months, are close to those obtained by Zanetta et al (1999), and compare favourably with those obtained in the other two studies (Dimopoulos et al, 2002; Choi et al, 2006). Despite a higher proportion of patients who underwent pelvic irradiation earlier (79\%), compared with the Italian study (Zanetta et al, 1999) (69\%), our results were not inferior, as the doses of drugs applied were not compromised, and this was reflected by the $21 \%$ incidence of febrile neutropenia despite routine prophylactic G-CSF. However, the majority of these febrile neutropenic episodes were managed uneventfully in the outpatient setting. Despite the limitations of inter-study comparisons, ORR were inferior in the studies by Dimopoulos et al (2002) and Choi et al (2006), presumably as a result of significant under-dosing, an arbitrarily selected lower dose intensity in the first study (4-week interval) and lower doses of drugs in the second study. In the latter study, significant under-dosing was reflected by the low incidence of grade 3-4 neutropenia, that is $11 \%$ (Choi et al, 2006). However, despite the higher ORR in our study, PFS and OS figures were comparable 
between this study and that by Dimopoulos et al (2002), presumably as a result of differing patient populations enrolled; more patients in this study failed within earlier radiation field, that is $60 v s 49 \%$, and more patients in the study by Dimopoulos et al (2002) had non-squamous histologies, 17 vs 32\%.

Results between studies may vary as a consequence of the inclusion of different proportions of patients exposed to earlier pelvic radiotherapy, differences in the PS of enrolled patients, variable inclusion of patients having failed within or outside the radiation field, doses of drugs applied, and histologic types treated (squamous vs other). Moreover, in one of the above studies, the so-called radiation-free interval (time elapsed from previous pelvic radiotherapy to recurrence, $<12 v s \geqslant 12$ months) seemed to have an important role in outcome after TIP chemotherapy (Zanetta et al, 1999).

The TIP regimen has been applied as neoadjuvant induction chemotherapy in patients with previously untreated inoperable localised cervical carcinoma by the above-referred Italian cooperative group (Zanetta et al, 1998). After an impressive pathological response of $34 \%$, the investigators of SNAP (Studio Neo-Adjuvante Portio) proceeded to a phase II randomised study of neoadjuvant chemotherapy evaluating TIP $v s$ the doublet of ifosfamide-cisplatin (IP), and illustrated the superiority of TIP $v s$ IP with an optimal pathological response (OPR) of 48 vs $22 \%$, respectively (Buda et al, 2005). Given the above results, a subsequent randomised study by the same group, SNAP-02, compared TIP with TP in an identical setting of neoadjuvant induction chemotherapy and confirmed once again the superior efficacy of TIP $v s$ TP; OPR $43 \%$ vs $23 \%$, respectively (Lissoni et al, 2009). There are no studies so far that have compared in a randomised manner TIP $v s$ TP or IP in advanced/metastatic cervical cancer. Moreover, in general, there is a paucity of studies comparing three-drug with two-drug regimens in an advanced/metastatic setting, and only one such study has compared bleomycin-

\section{REFERENCES}

Buda A, Fossati R, Colombo N, Fei F, Floriani I, Gueli Alletti D, Katsaros D, Landoni F, Lissoni A, Malzoni C, Sartori E, Scollo P, Torri V, Zola P, Mangioni C (2005) Randomized trial of neoadjuvant chemotherapy comparing paclitaxel, ifosfamide, and cisplatin with ifosfamide and cisplatin followed by radical surgery in patients with locally advanced squamous cell cervical carcinoma: the SNAP01 (Studio Neo-Adjuvante Portio) Italian Collaborative Study. J Clin Oncol 23: 4137-4145

Bunnell CA, Thompson L, Buswell L, Berkowitz R, Muto M, Sheets E, Shulman LN (1998) A phase I trial of ifosfamide and paclitaxel with granulocyte-colony stimulating factor in the treatment of patients with refractory solid tumors. Cancer 82: $561-566$

Cervellino JC, Araujo CE, Pirisi C, Sanchez O, Brosto M, Rossi R (1990) Ifosfamide and mesna at high doses for the treatment of cancer of the cervix: a GETLAC study. Cancer Chemother Pharmacol 26(Suppl): S1 - S3

Choi CH, Kim TJ, Lee SJ, Lee JW, Kim BG, Lee JH, Bae DS (2006) Salvage chemotherapy with a combination of paclitaxel, ifosfamide, and cisplatin for the patients with recurrent carcinoma of the uterine cervix. Int $J$ Gynecol Cancer 16: 1157-1164

Cox DR (1970) The Analysis of Binary Data. Methuen: London, UK

Dimopoulos MA, Papadimitriou CA, Sarris K, Aravantinos G, Kalofonos C, Gika D, Gourgoulis GM, Efstathiou E, Skarlos D, Bafaloukos D (2002) Combination of ifosfamide, paclitaxel, and cisplatin for the treatment of metastatic and recurrent carcinoma of the uterine cervix: a phase II study of the Hellenic Cooperative Oncology Group. Gynecol Oncol 85: 476-482

Eisenhauer EA, ten Bokkel-Huinik WW, Swenerton KA, Gianni L, Myles J, van der Burg ME, Kerr I, Vermorken JB, Buser K, Colombo N, Bacon M, Santabarbara P, Onetto N, Winograd B, Canetta R (1994) EuropeanCanadian randomized trial of paclitaxel in relapsed ovarian cancer: high-dose versus low-dose and long versus short infusion. J Clin Oncol 12: $2654-2666$

Herod J, Burton A, Buxton J, Tobias J, Luesley D, Jordan S, Dunn J, Poole CJ (2000) A randomised, prospective, phase III clinical trial of primary bleomycin, ifosfamide and cisplatin (BIP) chemotherapy ifosfamide-cisplatin (BIP) with IP, showing no benefit for the triplet regimen, pointing rather to the lack of efficacy of bleomycin as a single agent in advanced cervical cancer (Herod et al, 2000). It is believed that three-drug regimens, although more efficacious than two-drug regimens at the expense of increased toxicity, do not ultimately prolong PFS or OS in advanced/metastatic disease. In this setting, the TP doublet has shown to prolong median PFS over single-agent cisplatin (Moore et al, 2004), and the topotecancisplatin two-drug regimen has yielded improved median PFS and OS (Long et al, 2005).

With increasing numbers of patients who receive concurrent chemoradiotherapy with cisplatin as standard primary treatment for locally advanced cervix cancer since 1999-2000, when the combination emerged as standard, the RR, PFS, and OS rates for single-agent cisplatin have declined in relapsing patients, and a relative cisplatin resistance may explain the differences seen in recent phase III trials comparing combination chemotherapy with single-agent cisplatin. However, as explained theoretically above, the TIP combination may overcome resistance to cisplatin at least partially. A recent GOG study (GOG-204) - the largest phase III randomised trial in recurrent/metastatic cervical cancer - compared four platinum-based doublets with the reference arm of paclitaxelcisplatin, which was found to be not inferior to the three investigational arms (Monk et al, 2008). Moreover, another GOG phase II study (GOG-227C) of targeted anti-vascular therapy (bevacizumab $15 \mathrm{mg} \mathrm{kg}^{-1}$ ) in this patient population showed activity comparable with cytotoxics and was well tolerated (Monk et al, 2009).

Our results highlight the important activity of TIP combination in relapsed/metastatic cervical cancer, even in cases with recurrences within previously irradiated pelvis, however, at the cost of increased but manageable haematologic toxicity, and point to the design of randomised phase III studies comparing TIP with doublets in appropriately selected patients with advanced/metastatic cervical cancer. followed by radiotherapy versus radiotherapy alone in inoperable cancer of the cervix. Ann Oncol 9: 1175-1181

Kaplan EL, Meier P (1958) Non-parametric estimation from incomplete observations. J Am Stat Assoc 53: $457-481$

Kosmas C, Tsavaris N, Polyzos A, Malamos NA, Katsikas M, Antonopoulos MJ (2000a) Phase I study of dose-escalated paclitaxel, ifosfamide, and cisplatin (PIC) combination chemotherapy in advanced solid tumors. Br J Cancer 82: 300-307

Kosmas C, Tsavaris N, Polyzos A, Kalofonos HP, Sepsas E, Malamos NA, Vadiaka M, Dosios T, Antonopoulos MJ (2000b) A phase II study of paclitaxel-ifosfamide-cisplatin (PIC) combination in advanced nonsmall cell lung cancer. Cancer 89: 774-782

Kosmas C, Tsavaris NB, Malamos NA, Vadiaka M, Koufos C (2001) A phase II study of paclitaxel-ifosfamide-cisplatin (PIC) as second-line treatment in relapsed small-cell lung cancer. J Clin Oncol 19: 119-126

Kudelka AP, Winn R, Edwards CL, Downey G, Greenberg H, Dakhil SR Freedman RS, LoCoco S, Umbreit J, Delmore JE, Arbuck S, Loyer E, Gacrama P, Fueger R, Kavanagh JJ (1997) An update of a phase II study of paclitaxel in advanced or recurrent squamous cell cancer of the cervix. Anticancer Drugs 8: 657-661

Liebmann JE, Fisher J, Teague D (1994) Sequence dependence of paclitaxel (Taxol) combined with cisplatin or alkylators in human cancer cells. Oncol Res 6: $25-31$

Lissoni A, Zanetta G, Losa G, Gabriele A, Parma G, Mangioni C (1996) Phase II study of paclitaxel as salvage treatment in advanced endometrial cancer. Ann Oncol 7: 861-863

Lind MJ, McGowan AT, Hadfield JA, Thatcher N, Crowther D, Fox BW (1989) The effect of ifosfamide and its metabolites on intracellular glutathione levels in vitro and in vivo. Biochem Pharmacol 38: $1835-1840$ Lissoni AA, Colombo N, Pellegrino A, Parma G, Zola P, Katsaros D, Chiari S, Buda A, Landoni F, Peiretti M, Dell'anna T, Fruscio R, Signorelli M, Grassi R, Floriani I, Fossati R, Torri V, Rulli E (2009) A phase II, randomized trial of neo-adjuvant chemotherapy comparing a three-drug 
combination of paclitaxel, ifosfamide, and cisplatin (TIP) versus paclitaxel and cisplatin (TP) followed by radical surgery in patients with locally advanced squamous cell cervical carcinoma: the Snap-02 Italian Collaborative Study. Ann Oncol 20: 660-665

Long III HJ, Bundy BN, Grendys Jr EC, Benda JA, McMeekin DS, Sorosky J, Miller DS, Eaton LA, Fiorica JV (2005) Randomized phase III trial of cisplatin with or without topotecan in carcinoma of the uterine cervix: a Gynecologic Oncology Group study. J Clin Oncol 23: $4626-4633$

McGuire WP, Blessing JA, Moore D, Lentz SS, Photopulos G (1996) Paclitaxel has moderate activity in squamous cervix cancer. J Clin Oncol 14: $792-795$

Monk BJ, Sill M, McMeekin DS, Cohn DE, Ramondetta L, Boardman CH, Benda J (2008) A randomized phase III trial of four cisplatin (CIS) containing doublet combinations in stage IVB, recurrent or persistent cervical carcinoma: a gynecologic oncology group (GOG) study. J Clin Oncol 20(Suppl); abstract no. LBA5504

Monk BJ, Sill MW, Burger RA, Gray HJ, Buekers TE, Roman LD (2009) Phase II trial of bevacizumab in the treatment of persistent or recurrent squamous cell carcinoma of the cervix: a gynecologic oncology group study. J Clin Oncol 27: 1069-1074

Moore DH, Blessing JA, McQuellon RP, Thaler HT, Cella D, Benda J, Miller DS, Olt G, King S, Boggess JF, Rocereto TF (2004) Phase III study of cisplatin with or without paclitaxel in stage IVB, recurrent, or persistent squamous cell carcinoma of the cervix: a Gynecologic Oncology Group study. J Clin Oncol 22: 3113-3119

Omura GA, Blessing JA, Vaccarello L, Berman ML, Clarke-Pearson DL, Mutch DG, Anderson B (1997) Randomized trial of cisplatin versus cisplatin plus mitolactol versus cisplatin plus ifosfamide in advanced squamous carcinoma of the cervix: A Gynecologic Oncology Group study. J Clin Oncol 15: 165-171

Parker RJ, Dabholkar MD, Lee KB, Bostick-Bruton F, Reed E (1993) Taxol effect on cisplatin sensitivity and cisplatin cellular accumulation in human ovarian cancer cells. J Natl Cancer Inst Monogr 15: 83-88

Papadimitriou CA, Sarris K, Moulopoulos LA, Fountzilas G, Anagnostopoulos A, Voulgaris Z, Gika D, Giannakoulis N, Diakomanolis E,
Dimopoulos M (1999) Phase II trial of paclitaxel and cisplatin in metastatic and recurrent carcinoma of the uterine cervix. J Clin Oncol 17: $761-766$

Reed E, Kohn EC, Sarosy G, Dabholkar M, Davis P, Jacob J, Maher M (1995) Paclitaxel, cisplatin, and cyclophosphamide in human ovarian cancer: molecular rationale and early clinical results. Semin Oncol 22(Suppl 6): $90-96$

Rose PG, Blessing JA, Gershenson DM, McGehee R (1999) Paclitaxel and cisplatin as first-line therapy in recurrent or advanced squamous cell carcinoma of the cervix: a Gynecologic Oncology Group study. J Clin Oncol 17: 2676-2680

Rowinsky EK, Chaudhry V, Forastiere AA, Sartorius SE, Ettinger DS, Grochow LB, Lubejko BG, Cornblath DR, Donehower RC (1993) Phase I and pharmacologic study of paclitaxel and cisplatin with granulocyte colony-stimulating factor: neuromuscular toxicity is dose-limiting. J Clin Oncol 11: 2010-2020

Simon R (1989) Optimal two-stage designs for phase II clinical trials. Control Clin Trials 10: $1-10$

Sutton GP, Blessing JA, McGuire WP, Patton T, Look KY (1993) Phase II trial of ifosfamide and mesna in patients with advanced and recurrent squamous carcinoma of the cervix who have never received chemotherapy. Am J Obstet Gynecol 168: 805-807

Thigpen T, Vance RB, Khansur T (1995) The platinum compounds and paclitaxel in the management of carcinomas of the endometrium and the uterine cervix. Semin Oncol 22: 67-75

Tsavaris N, Polyzos A, Kosmas C, Giannikos L, Gogas J (1997) A feasibility study of one-hour paclitaxel infusion in solid tumors. Cancer Chemother Pharmacol 40: $353-357$

Zanetta G, Fei F, Parma G, Balestrino M, Lissoni A, Gabriele A, Mangioni C (1999) Paclitaxel, ifosfamide and cisplatin (TIP) chemotherapy for recurrent or persistent squamous-cell cervical cancer. Ann Oncol 10: $1171-1174$

Zanetta G, Lissoni A, Pellegrino A, Sessa C, Colombo N, Gueli-Alletti D, Mangioni C (1998) Neoadjuvant chemotherapy with cisplatin, ifosfamide and paclitaxel for locally advanced squamous-cell cervical cancer. Ann Oncol 9: 977-980 